\title{
Impact of the Game Cyberpunk 2077 on Cyberpunk Culture
}

\author{
${ }^{1}$ Walnut Grove Secondary School, Langley, BC, V1M 2N7, Canada \\ ${ }^{2}$ Alcanta International College, Guangzhou, Guangdong, China \\ *Corresponding author. Email: guanghua.ren@gecacademy.cn \\ These authors contributed equally.
}

Jialu Sun ${ }^{1, \dagger}$, Zhaotong $\mathrm{Zhou}^{2, *}, \dagger$

\begin{abstract}
Cyberpunk has been a popular word in contemporary world. Most individuals may consider that Cyberpunk is an incredible new word. However, Cyberpunk appears myriad years ago as a distinct forms to now. While there are various ways to define Cyberpunk, the game Cyberpunk 2077 is the most remarkable form that shown in public. As a new form of Cyberpunk, we have done research on how this game influence the Cyberpunk culture. It provides a more direct and strong tone visual for audience rather than just reading it. In addition, this tone also brings people reflections on a positive side of future world.
\end{abstract}

Keywords: Cyberpunk 2077, Cyberpunk Culture, future world.

\section{INTRODUCTION}

Cyberpunk has been a rising trend in recent years, and the genre is gaining growing popularity among young people. There is a wide variety of cyberpunk cultural works, and there are countless social media applications, such as movies, novels, and games based on this culture. Games is especially influential factors to the trend of Cyberpunk. The well-known game Cyberpunk 2077 is a famous representation of Cyberpunk games. Cyberpunk 2077 is an action roleplaying game designed and created in a cyberpunk style, developed by CD Project RED. Cyberpunk 2077 is an open-world game set in the City of Night, where power changes and body transformation are constant themes. Play as an ambitious mercenary: $\mathrm{V}$, in pursuit of a unique implant - the key to immortality. The game restores most settings in classical Cyberpunk, spreading Cyberpunk style to the public. Cyberpunk 2077 was the biggest winner of Cologne 2020 with five best of the best awards, including Best Game of Cologne 2020, Cologne Game Show Consumer "Most Anticipated Game" and Best Sony PlayStation Game, which shows its popularity. Since people are attracted by Cyberpunk 2077, many individuals start to search information about precisely Cyberpunk definition. Cyberpunk is originally a sub-genre of scientific fiction, so it first appears as a form of fiction. As the culture develop, Cyberpunk usually refers to the combination and use of low-end life and high-end top technology, and the collision and contrast of these two elements bring people a cool and colourful visual feast and innovative and unique ideas. Although more people are willing to know about Cyberpunk culture, Cyberpunk 2077 have increasingly more influence to public than Cyberpunk works do. Most people think of the game instead of traditional Cyberpunk when they hear the word "Cyberpunk". There are several notable reasons of why Cyberpunk 2077 can rapidly facilitate the development of Cyberpunk culture. Games is an attracted form for spreading a culture, many people will be addicted to the game. In addition, under the Covid-19 circumstance, Cyberpunk 2077 gain a great opportunity to develop.

Cyberpunk 2077 is a very successful and wellknown action game. In fact, it was announced back in 2012 and the first concept trailer was released the following year, but developer CD Project Red didn't reveal any more information about the game for five years after that. Cyberpunk 2077 did not enter preproduction until after the development team completed The Witcher 3: Wild Hunt's final sourcebook, The Witcher 3: Wild Hunt - Blood and Wine, in 2016. Development of Cyberpunk 2077 reportedly reached a milestone in late 2017. During China joy 2019, CD Project Red executives said in an interview that the Chinese content, including voice acting, was the studio's 
largest ever, with more than 150 people involved in the game's Chinese production, which took nearly eight months to record more than 100,000 lines, mainly by CD Project Red's Chinese branch in Shanghai. [1] In October 2020, CD Project RED officially completed the development of Cyberpunk 2077 for pressing and production. Cyberpunk 2077 was announced in May 2012 and officially confirmed for Microsoft Windows in 2013. On the first day of Cyberpunk 2077's release, CD Project announced that 8 million copies of the game had been pre-ordered across all platforms. [2] And on the first day of release, the game successfully earned back the game's development costs and marketing expenses. According to Steam, there were 1,003,262 players online at the peak on the first day of the launch, making it the single game with the highest number of simultaneous online players on the platform. [3] And why Cyberpunk 2077 is so hot, I think there are several reasons. Firstly, the market lacks cyberpunk new era of painting style game. As we all know, cyberpunk themes are more concentrated in novels, board games and movies, and there is a lack of excellent and well-known works in games, so a novel and remarkable cyberpunk style game can greatly attract the attention and interest of the public. In addition, the game company CD Project has an excellent reputation, and everyone is very supportive of it. If people have played the Witcher series trilogy played, you know that the Polish stupid donkey is a very powerful company, the Witcher trilogy is stupid donkey do the first three games, each one put on sale time is a masterpiece, the Witcher 3 can even be called a masterpiece. The Witcher 3 can even be called a masterpiece. So naturally, people are very excited about the games it will make later.

\section{LITERATURE REVIEW}

Cyberpunk culture have shown in various forms throughout the history. Myriad people are confused about Cyberpunk specifically because of its variation in definition and forms. There is still difficulty for people to define cyberpunk precisely. Trying to define Cyberpunk is a difficult task. In short, however, Cyberpunk refers to both a culture and a genre [4]. That is one of the reasons why when someone talking about Cyberpunk, people frequently think of the game. Although the current mainstream definition of cyberpunk culture is all about the visual element, we still generally believe that Cyberpunk's idea was started in words [5].

Cyberpunk is originally a subgenre of science fiction that keeps a mission of combining high tech and low life. There are several prominent Cyberpunk novels such as Neuromancer by William Gibson. The novel tells the story of a washed-up computer hacker hired by a mysterious employer to pull off the ultimate hack [6]. Authors in such novels describe a perfectly dystopia world by writing characters' garments, futurism landscape, and high-tech elements. This did not become popular because people have never seen this type of friction before, or they may simply consider it is futurism novels. Since this form cannot allows most individuals to know about the style, someone bring fictions to screen, and Cyberpunk films appears. Most Cyberpunk movies are adapted from famous friction. Take Blade Runner 2049, for instance. It shows the best Cyberpunk visual ever for audience from its uses of Cyberpunk elements. It contains excellent Cyberpunk visual on screens and simultaneously keeps the complete story [7]. Comments from certain Cyberpunk enthusiast describe it a spires of aesthetics creation. This was also beneficial to original friction because audience who like movies will go to read the novels, which facilitate Cyberpunk culture. Once Cyberpunk become increasingly more popular, it becomes a game, a style in fashion industry, and style of artwork. People know more elements in Cyberpunk rather than a style of friction. Certain illustrator start drawing pictures base on descriptions in novels. Cyberpunk becomes a popular style since individuals have understandings visually. More people have discussion on Cyberpunk but about visual elements instead of written words. Movies and cartoons attract people increasingly than books because audience can directly see Cyberpunk elements rather than imagine it while they read frictions. From my perspective, movie is the first breakthrough of Cyberpunk culture, and the game brings it to the peak. Some scholars study cyberpunk in China. Cyberpunk culture spread to China in the late 20th century and became popular among Chinese youth in the early $21 \mathrm{st}$ century. In the 21 st century, China's research and development of artificial intelligence has enriched young people's imagination of the future and made them think about cyberpunk culture. On Chinese social media, young Chinese are enthusiastically discussing cyberpunk culture. They are more inclined to consumerism and pay more attention to the changes in life brought by future technology, abandoning the rebellious and dystopian punk kernel in western cyberpunk works [8]. Some scholars believe that the two important characteristics of Cyberpunk culture are the expression of binary opposition and human glory. Two binary opposition frequently appear in cyberpunk culture: the binary opposition between humans and robots, and the binary opposition between officialdom and the masses. And these are binary opposition between "centre" and "edge". Most cyberpunk work today redefines "human" in terms of duality. For example, a robot can also give itself a personality and become a new identity. This is allowed and even supported in cyberpunk culture [9]. Some scholars also put forward cyberpunk culture as a wake-up call for mankind. Nowadays, people are addicted to virtual reality and simulation games constructed in cyberspace, and even memory is becoming electronic. Cyber punk is 
immersed in the magnificent network space gradually fuzzy real and unreal human provides an opportunity to examine itself, in order to create a dystopian future of the world to alert the world: every progress has shortcomings, cyber punk questions are human will encounter in the future and is unable to avoid [10].

\section{RESULTS \& DISCUSSION}

With the popularity of Cyberpunk 2077 game, it has also brought far-reaching effects to the cyberpunk culture. Firstly, the game spread cyberpunk culture more widely. Originally, cyberpunk was only spread among the circle of science fiction enthusiasts, but because of its very strong visual impact, it slowly became popular among the advertising circle, and then became better known. The high-tech future civilization and the suffering people who are so poor that they lose their value form a strong visual impact, leaving a deep impression on everyone who sees cyberpunk for the first time. Slowly, more people learn about cyberpunk culture in cyberpunk games for the first time. At the same time, a large part of the population comes to play the game because they are attracted by the cyberpunk culture and experience the cyberpunk world more deeply and immersivity. Whether they are game lovers or culture enthusiasts, this game effectively meets the needs of both groups of people. As more and more people become familiar with Cyberpunk 2077, people are becoming more passionate and willing to learn about cyberpunk culture. In addition, the world created by Cyberpunk 2077 and the cyberpunk world are perfectly integrated, bringing people an immersive virtual world experience. "Cyber" means "digital network", and you can relate it to the virtual cyberspace that often appears in the "cyberpunk" worldview. Viewers who have seen The Matrix series will be impressed by the cyberspace composed of lines of green code, which is, in a way, a visual symbol of "cyberpunk" culture. The unique visual effects created by this virtual space are naturally presented in Cyberpunk 2077, where players enter a virtual cyberspace as the game's plot progresses, exploring the truth about a series of events that happened to the protagonist and revealing the unknown side of the "City of Night" in all its glory. The "City of Night" is a virtual cyberspace in which the protagonist explores the truth about a series of events that happened to him [7]. But in the broader context of cyberpunk, the word "Cyber" is more often used as a shorthand for "cybernetic". It can be understood, on the one hand, as the existence of a multinational monopoly with absolute control over society in the "cyberpunk" world. On the other hand, it can also be interpreted as a reflection on the value of human existence in a future world where human prosthetic transformation is already highly developed and has become a common social phenomenon. For the discussion of related issues, "Cyberpunk 2077" also through a very in-depth plot, to show players their understanding of the "prosthetic transformation of humans" this science fiction scenario. In the context of Cyberpunk, the typical characteristics of Punk are "anti-corporate", "militant", and "anarchic". "And the pursuit of anarchy. Specifically implemented into the worldview of Cyberpunk 2077 and the logic of the characters' actions, the game needs to be able to make a complex enough differentiated visual design, as well as a variety of characters and storylines with the spirit of "punk". The world of Cyberpunk 2077 necessarily requires a clear dichotomy of "order" and "chaos". Through a variety of visual content design and scene details, to create a violent conflict between the two, this is the "Cyberpunk 2077" from the visual effects to present the "City of Night" look. Last but not least, the cyberpunk series is a product of its time. In the face of the coming or already arrived high-tech era, people are full of brilliant visions and inevitable worries: will the high-tech future replace the thinking of the human brain? Can robots and humans always live together in peace and eternity? The pioneers, with a rebellious and exploratory mindset, clearly gave a negative answer. The spiritual core of cyberpunk is antiutopia, which is used as a spiritual structure. In the world of high technology, human beings gradually move away from nature and indulge in this world, slowly human beings start to feel lost and confused, and by extension, human beings start to satisfy their desires in order to fill their inner emptiness and use technology to deceive themselves. These are reflected in the lives of people, which itself has a variety of contradictions. These also deduce the rebellion, for example, the contrast between the tall modern buildings of the city and the cold and damp slums in the game, the conflict contradiction violence hidden under the prosperous appearance. Cyberpunk 2077 actually reflects people's deep thinking about the high-tech era through the virtual cyberpunk world in the game, while the high-tech low quality of life and the future does not seem to be as satisfactory as it should be. Such warnings and deep thoughts are really cyberpunk and the game brings people to think about the future changes in the world.

The worlds of many seemingly unattainable works of science fiction are people's future worlds. As in Cyberpunk 2077, even though the world of the game is full of exaggerated, unrealistic scenarios, it is a symbol of the combination of low-quality life and high technology in the future. People seem to be playing the game, but also can be said to experience and feel the virtual world of the future. Cyberpunk 2077 is also the reason for the popularity, more than the times given, it stands in the chaotic zone of reality and fantasy to reflect the future and remind mankind of the changing technological era. 


\section{CONCLUSION}

Cyberpunk 2077 has in a sense driven even more the development of cyberpunk culture, making the cyberpunk style a rapidly growing trend in recent years. Although it is widely used in advertising, movies, novels and other social media to express a futuristic, near-perfect concept, many consider the cyberpunk world created in the Cyberpunk 2077 games to be unprecedented and mind-blowing. Cyberpunk 2077 brings people more than its superficially shallow key elements, such as bleak rainy nights, brilliant neon lights, towering skyscrapers and giant billboards, and certain scenes of decay that contrast sharply with them. It perfectly illustrates the core theme of cyberpunk is to reflect on the dark side of science and technology and its relationship with human beings by depicting the decadent plight of the future world of "high tech low life" after the overdevelopment of science and technology. If the birth of cyberpunk culture in the last century was a reflection of the concern and reliance on computer technology, then works like Cyberpunk 2077 represent a new era of concern about the negative effects of rapid technological development. If human beings do nothing to restrain the negative effects of high technology and new technologies, then no matter how good the initial intention is, it may lead to catastrophic consequences. This anti-utopian thinking has a great deal of ambiguity and sentimentality, rather than an explicit rejection and confrontation with technology. The growing popularity of this style has led people to think about the future of technological development and the improvement of quality of life. All of this is reflected in the game, and cyberpunk has a highly unified science fiction aesthetic system from form to content to theme. The nature of video games allows creators to create a world that can be experienced firsthand, and in the process, feel the core of the cyberpunk world structure and ideas. Cyberpunk 2077 does this very well, showing the future of a fantasy capitalist economy in a way that is unique to video games.

\section{REFERENCES}

[1] Morris, Tatiana. "New Cyberpunk 2077 details suggest mid-2019 release". GameZone. (2017).

[2] Holt, Kris. "'Cyberpunk 2077' won't require a highend gaming rig". Engadget. (2020).

[3] Robinson, Andy. "Cyberpunk 2077 interview: 'There are many surprises left"'. Video Games Chronicle. (2019).

[4] Sara, et al. "What Is Cyberpunk?" Neon Dystopia, (2015).

[5] Douban, "A Rediscovery of the Nature of Cyberpunk Culture and Exploration in the Cinematic Game--under the Idea of Technology
Reflexivity."

https://www.douban.com/review/13204501/.

[6] William Gibson," Neuromancer.", https://williamgibson.fandom.com/wiki/Neuroman cer.

[7] Veritas, Isaac L. Wheeler. "Blade Runner 2049 Mature Cyberpunk for the Modern Era." https://www.neondystopia.com/cyberpunk-moviesanime/blade-runner-2049-mature-cyberpunk-forthe-modern-era/.

[8] Jiang Yuqin. Representation and Discourse Construction of Cyberpunk Culture in China [J]. Journal of Shenzhen University (Humanities and Social Sciences edition), 38(05):143-151. (2019)

[9] Zhang Qiqi. Binary Opposition -- Cyberpunk humanistic Interpretation. Popular Literature and Art (14),22-23. (2019).

[10] Ling Meng. Cyberpunk: A Disordered, dystopian future. Art Technology (08),133. (2017). 